\title{
Resolution of cell-mediated airways diseases
}

\author{
Carl G Persson*1 and Lena Uller²
}

\begin{abstract}
"Inflammation resolution" has of late become a topical research area. Activation of resolution phase mechanisms, involving select post-transcriptional regulons, transcription factors, 'autacoids', and cell phenotypes, is now considered to resolve inflammatory diseases. Critical to this discourse on resolution is the elimination of inflammatory cells through apoptosis and phagocytosis. For major inflammatory diseases such as asthma and COPD we propose an alternative path to apoptosis for cell elimination. We argue that transepithelial migration of airway wall leukocytes, followed by mucociliary clearance, efficiently and non-injuriously eliminates pro-inflammatory cells from diseased airway tissues. First, it seems clear that numerous infiltrated granulocytes and lymphocytes can be speedily transmitted into the airway lumen without harming the epithelial barrier. Then there are a wide range of 'unexpected' findings demonstrating that clinical improvement of asthma and COPD is not only associated with decreasing numbers of airway wall inflammatory cells but also with increasing numbers of these cells in the airway lumen. Finally, effects of inhibition of transepithelial migration support the present hypothesis. Airway inflammatory processes have thus been much aggravated when transepithelial exit of leukocytes has been inhibited. In conclusion, the present hypothesis highlights risks involved in drug-induced inhibition of transepithelial migration of airway wall leukocytes. It helps interpretation of common airway lumen data, and suggests approaches to treat cell-mediated airway inflammation.
\end{abstract}

\section{Introduction}

Mechanisms active in development of cell-mediated airways disease such as asthma and chronic obstructive pulmonary disease (COPD) may differ from mechanisms involved in exacerbations of these diseases. Different mechanisms again would be involved in resolution of inflammation and healing of the diseased airways. A major aspect of resolution is the elimination of inflammatory cells from the diseased airway wall. This is accomplished, it is thought, by activation of a programmed cell death (apoptosis) followed by 'silent' elimination through phagocytosis of the apoptotic cells. Based on their potential to induce apoptosis of eosinophils and lymphocytes, and increase phagocytosis of apoptotic leukocytes, the mainstay airway anti-inflammatory drugs, glucocorticoids, are considered as pro-resolution drugs ([1], and references cited therein). However, it appears that few in vivo data have been publicised during the last two decades in support of a significant role of leukocyte apoptosis in airways diseases, whether steroid treatment has been involved or not. This limited support for a central

* Correspondence: carl.persson@med.lu.se

${ }^{1}$ Department of Clinical Pharmacology, Lund University Hospital, S-22185 Lund, Sweden

Full list of author information is available at the end of the article dogma on resolution may increasingly be realised by authors involved in research on respiratory disorders: Downey et al [2] recently observed that findings of reduced neutrophil apoptosis in resolving exacerbations of cystic fibrosis "seem counter intuitive as it should be expected that neutrophil apoptosis should have increased to aid resolution of infection and inflammation". On a slightly different note Porter [3], examining transepithelial migration of lymphocytes in vitro, stated that it is widely assumed that the clearance of these cells from inflamed airway tissues involves apoptosis thus "ignoring a potentially very important exit across the bronchial epithelial barrier". This exit has been named 'luminal entry'. Analogous to the exit of cells across the venular endothelial barrier it may also be called 'transepithelial egression', 'transepithelial migration', or 'transmigration'.

Here we discuss the possibility that transepithelial migration of infiltrated airway wall leukocytes is important for resolution of airway inflammation. The present review is guided primarily by actual, independent in vivo observations [4-6]. As such it may differ dramatically from current mechanism-driven approaches by which in vivo observations, too uncritically, may have to comply with the accepted dogma. After introductory paragraphs on development of the present hypothesis and on the rap- 
idly growing interest in resolution of inflammation, we discuss flaws in the studies that have suggested that apoptosis/phagocytosis are key drivers for inflammation resolution in airways diseases. Then we provide a large amount of circumstantial evidence in support of the alternative concept of transepithelial migration/mucociliary clearance as a means of inflammation resolution. Our focus is on observations in patients with inflamed airways. This approach is complemented by in vivo data generated in animal models on inflammation resolution and its inhibition. Reflecting the current lack of an accepted research paradigm in the field, mechanisms involved in transepithelial migration have rarely been explored as a mode of resolving airway tissue inflammation. This state of the art is reflected in the present review by a frugal account of in vitro observations. It is largely for future studies to delineate details of molecular regulation of elimination of leukocytes by their migration through airway tissue components and across the epithelial lining.

\section{Development of a hypothesis}

Together with Jonas Erjefält we have examined numerous airway tissues in health and disease without being able to support the proposed role of granulocyte apoptosis. Instead our work led to the identification of primary cytolysis, without prior apoptosis, as an in vivo paradigm for eosinophil death in the human airway wall $[7,8]$. This fate had little to do with resolution but was a mode of cell activation causing the release of clusters of free eosinophil granules $[7,8]$. For non-injurious elimination of airway wall eosinophils we had to look elsewhere. The old literature on asthma [9] was somewhat helpful. Around the turn of the $19^{\text {th }}$ century it was noted that profuse sputum eosinophilia accompanied the clinical improvement of severe asthma. Hence, there is nothing novel in the thinking that elimination of numerous leukocytes from diseased airways can occur via the airway lumen route.

Initially we hypothesised that transepithelial migration was one of several modes of elimination of airway wall eosinophils along with apoptosis and cytolysis $[7,10]$. Further unexpected failures to detect apoptotic cells in vivo made it apparent that the transepithelial pathway could be the major mode of elimination of airway wall granulocytes [6,8,11-13]. Similarly, the unexpected failure to detect oedema at extravasation of plasma in the airway mucosa had once led to the observation that extravasated, non-sieved plasma could swiftly disappear from the airway wall by moving across an intact epithelial lining [14]. Aiding the transepithelial route of cell and protein elimination, the airway epithelium strongly favours the passage of leukocytes and plasma in the physiological basal to apical direction [14-20].

Both infiltrated leukocytes and extravasated plasma proteins can be transported by lymph flow but this is an exceedingly slow elimination process compared to the exit through transepithelial egression-exudation [13,21]. As demonstrated by Lehman et al [20] for lymphocytes, cells can move from the airway lumen across the alveolar (not the bronchial) epithelium, migrate to regional lymph nodes, and rejoin the systemic systems. In allergen-challenged mice lung regional lymph nodes become heavily infiltrated also with eosinophils [22] but this pathway can explain only a minor part of the disappearance of these cells from the airways [13]. Experiments by Buckley et al [23] and McGettrick et al [24] involving endothelial cell monolayers suggest the additional possibility that transmigrated neutrophils and lymphocytes, perhaps lymphocytes more than neutrophils, to varying degrees can transmigrate back in the reverse direction. If translated to in vivo these data mean that leukocytes could leave the inflamed airway tissue by reverse endothelial transmigration. The importance of this possibility is not known. In their recent editorial on resolution of inflammation, Haworth and Buckley [25] do not mention reverse endothelial migration of leukocytes.

Our continued studies of airways in vivo have specifically involved the early resolution phase as well as steroid treatment in animals and man $[26,27]$ but the findings do not support the assumed role of apoptosis [28-30]. For example, five days' topical steroid treatment of individuals with allergic rhinitis reduced the subepithelial eosinophilia more than the epithelial eosinophilia. This effect agreed with the possibility of eosinophils trafficking towards the airway lumen. Further, at this stage of a rapidly resolving eosinophilic allergic inflammation no apoptotic eosinophil (phagocytosed or non-phagocytosed) was detected in the airway tissue. The allergic inflammation had evoked a general increase of apoptotic cells in the diseased airway mucosa and these noneosinophilic apoptotic cells were significantly reduced by the steroid treatment, as were several other tissue signs of allergic inflammation [27]. As discussed below a wide range of clinical reports have failed to demonstrate clear roles of leukocyte apoptosis in airways diseases. We further note that many clinical observations, previously discussed as unexpected and puzzling data, actually support the transepithelial migration mode of resolving cellmediated airways disease. This particular role of transepithelial egression also helps explain significant findings in animal model studies. The present hypothesis needs consideration in current development of novel drugs that affect leukocyte trafficking. These aspects make it timely to review the area.

\section{Multifaceted interest in resolution of inflammation}

Infections, allergic reactions and a variety of other insults cause inflammation. Inflammation resolution involves normalisation of microcirculatory activities, loss of infiltrated cells, and healing of any injury that may have 
occurred. The resolution may not mean that everything returns to homeostasis because long after the inflammation has resolved significant changes in the innate responsiveness of cells such as the asthmatic epithelium may linger to meet the next insult somewhat differently $[31,32]$. It is well known that individual mediators, cytokines, and cells may have both pro- and anti-inflammatory facets. Recently, there have been intriguing attempts at identifying endogenous agents with particularly active roles in resolution of inflammation. Thus, there is focus on pro-resolution effects of IL-10 and TGF-beta, adenosine and prostaglandin D2, lipoxins and other lipid mediators $[1,33-35]$. Some of these regulatory molecules may live up to the actual meaning of the now almost obsolete name 'autacoids' (self remedy). Important roles of certain cells and cell phenotypes in resolution are also entertained with focus on regulatory $\mathrm{T}$ cells, macrophages, and neutrophils $[1,35]$. In addition, select transcription factors [36] and post-transcriptional regulons [37] are given roles in resolution of inflammation. This development has brought resolution hypotheses to the forefront of discussions of airways disease mechanisms [34,38]. Common to the rapidly growing, multifaceted literature on mechanisms of resolution of inflammatory disease processes is the centrality of leukocyte apoptosis followed by phagocytosis of the apoptotic leukocytes. Apoptosis mechanisms are consistently emphasized whereas it appears that a role of transepithelial cell migration may have been overlooked.

\section{Role of leukocyte apoptosis in airway lumen?}

Apoptosis of leukocytes in the more accessible airway lumen has been studied with the assumption that the findings are relevant for cells in the airway wall. However, clear distinction between findings in the airway lumen and observations in the blood-perfused airway wall is of fundamental importance here. Dead, apoptotic granulocytes cannot migrate. It is not likely, therefore, that the occurrence apoptotic leukocytes in the airway lumen can tell anything about apoptosis in the airway wall. What is then the role of apoptosis of the lumen cells in airways diseases? A widely quoted, uncontrolled study from 1996 [39] reported that steroid treatment increased the percentage of apoptotic eosinophils in the airway lumen. It was claimed that this action was important for the resolution of airway inflammation in asthma. In contrast, a subsequent placebo-controlled trial involving a high dose inhaled steroid found no increase in apoptotic eosinophils in sputum samples despite a reduction in sputum eosinophils [40]. In further contrast to predictions from in vitro findings, the number of sputum macrophages that had ingested eosinophils was reduced in the steroidtreated asthmatic individuals compared to placebo [40]. Inconclusive clinical observations of leukocyte apoptosis in the airway lumen have been reported not only in asthma [13,39-41] but also in COPD [13,41,42], cystic fibrosis [2,43], and bronchiectasis [44]. Matute-Bello and Martin [45], who originally discovered an anti-apoptotic action of BAL fluid in adult respiratory distress syndrome, have now argued that neutrophil apoptosis may have little to do with outcome. Findings in airway lumen in acute lung injury in newborn infants [46] may similarly disallow firm conclusions on roles of neutrophil apoptosis. Also, the hypothesis that the airway lumen milieu in COPD would promote neutrophil survival was not supported in studies where neutrophils were exposed to airway lumen fluids [42]. In summary, roles in disease for apoptosis and subsequent phagocytosis of apoptotic leukocytes in the airway lumen remain to be defined.

\section{Steroid-induced apoptosis of eosinophils, lymphocytes, and dendritic cells in the airway wall in vivo?}

The relatively rapid steady-state turnover of airway mucosal dendritic cells (Holt et al 94) is considered to reflect the need for continuous immune surveillance and emigration of these cells to regional lymph nodes. There are increased numbers of bronchial mucosal dendritic cells in asthma and they are downregulated by prolonged steroid treatment (Möller et al96). Mechanisms involved in this drug-induced elimination of dendritic cells remain unknown although in rats receiving a large systemic steroid dose apoptosis is responsible in part for the rapid loss of tracheal mucosal dendritic cells (Brokaw 1998). In vitro studies on steroid-induced apoptosis of dendritic cells are scarce whereas steroid-induced apoptosis of eosinophils and lymphocytes $[1,29,30]$ has received much attention. However, the reputed eosinophil apoptosisinducing effect of glucocorticoids has not been borne out in in-vivo studies of airway tissues $[8,11,13,26]$ nor could steroid-induced $\mathrm{T}$ cell apoptosis be consistently demonstrated in biopsies obtained from asthmatic $[47,48]$ and COPD patients [49]. Indeed, compelling evidence now appears to be lacking to show that infiltrated eosinophils and lymphocytes are eliminated from the airway wall through apoptosis followed by phagocytosis. Animal and human airway wall eosinophils seem to increase and decline without occurrence of detectible apoptotic eosinophils, whether phagocytosed or not $[7,8,13,27]$.

\section{Steroid-induced inhibition of neutrophil apoptosis in the airway wall in vivo?}

Steroid-induced attenuation of neutrophil apoptosis was demonstrated in vitro in 1995 [50]. This effect on cultured cells has since been considered to explain observations in vivo of airway wall neutrophilia induced by steroid treatment in both COPD [51-53] and asthma [5456]. However, as with steroid-induced increase in apoptosis of eosinophils and lymphocytes, the steroid-induced 
attenuation of neutrophil apoptosis has not been compellingly demonstrated in the diseased airway wall. Gizycki et al [51] examined the ultrastructure of neutrophils in COPD biopsy tissues. Since morphologic cell features accurately define apoptosis this technique should be ideal for assessing this fate of the neutrophils. However, no effect of steroid treatment on neutrophil apoptosis was observed. Gizycki et al concluded "the functional significance of the potential for steroids to reduce the clearance of neutrophils by their effect on apoptosis is unclear in vivo".

Little attention has been given to the alternative possibility that the steroid effect could reflect upregulation of neutrophil-retaining chemokines in the airway wall. Steroid treatment in mild asthma actually increases mucosal expression of major neutrophil attractants such as IL-8 and INF-gamma-inducible protein 10 [54]. In steroidtreated severe exacerbations of asthma, CXCL5-dependent mechanisms [56] may further contribute to recruiting and retaining the neutrophils in the airway wall. These actions alone suggest that steroids may reduce transepithelial migration of neutrophils. This possibility is now amply supported by clinical observations on cells in airway wall and lumen, respectively. Contrasting the steroid-induced airway wall neutrophilia [51-56] several human in vivo studies, involving steroid-treated COPD patients and other steroid-treated neutrophilic airway conditions [53,57-60], have now shown reduced airway lumen neutrophils. These reciprocal effects, convincingly confirmed in one and the same study [53], strongly suggest that steroid treatment reduces transepithelial migration of airway wall neutrophils. The significance of this steroid action is not known. However, it should be difficult to accept the conclusion that an anti-inflammatory effect of steroid treatment has been achieved merely based on reduced numbers of airway lumen neutrophils $(51,52)$.

\section{Transepithelial migration of leukocytes without harming the epithelial lining}

The passage of granulocytes such as eosinophils and neutrophils across the epithelium in asthma and COPD is thought to be part of pathogenic disease processes with a capacity to cause severe epithelial injury [15,61-63]. This view can be debated. For example, commonly obtained evidence of barrier dysfunction is based on reduced electrical resistance. However, the bioelectrical properties of the epithelial lining may not be equated with physiologically important barrier functions [64]. It is even possible that apical epithelial junction proteins including occludin can be reduced without undue effects on epithelial barrier function. Also, numerous eosinophils and neutrophils have been demonstrated to migrate into the airway lumen in animals and man in vivo without injuring the epithelium [16,65]. Thus, about 35000 eosinophils per minute and per $\mathrm{cm} 2$ mucosal surface area transmigrated across a normal, human airway-like, guinea-pig tracheal epithelial lining in vivo leaving ultrastructurally intact epithelial apical cell to cell contacts [16]. Similarly, bronchial instillation of LTB4 in human subjects and LPS in sheep produced transmigration of neutrophils into the airway lumen without evidence of epithelial injury [65]. Importantly, the transepithelial exit of cells as well as extravasated plasma proteins occur without increasing epithelial permeability in the reverse direction. The swift entry of cells and macromolecules into the airway lumen, without increasing the absorption rate of luminal macromolecules, tells about the plasticity or valve-like function of para-epithelial junctions [14,65]. This epithelial feature also explains why exudative allergic and inflammatory airways diseases do not exhibit increased absorption permeability; until proven otherwise asthma and allergic rhinitis may rather be characterised by reduced absorption of inhaled molecules in vivo $[14,66]$.

Granulocytes may seem guilty by their association with sites of epithelial injury. Yet, the relation could be the reverse in that epithelial cell injury can provide potent stimuli for recruiting activated neutrophils and eosinophils to the repair site and to the airway lumen [67]. Further work thus seems needed to determine under what circumstances a mere passage of leukocytes can harm the airway epithelial lining in health and disease. Studies are also warranted to better elucidate the non-injurious nature of transepithelial egression of leukocytes especially at resolution of airway inflammation.

\section{Transepithelial egression of inflammatory cells at clinical improvement of airways disease Eosinophils}

In animal models of allergic airway inflammation $[11,13,26]$ airway lumen eosinophilia has occurred during resolution when eosinophils have disappeared from the airway wall. We have found three clinical experimental studies where both airway wall and lumen eosinophils have been determined during the resolution phase. These studies involved allergen-challenged subjects with mild allergic asthma, It seems highly significant that all three studies consistently (and "unexpectedly") demonstrate that loss of infiltrated bronchial mucosal tissue eosinophils is associated with increased numbers of eosinophils in the bronchial lumen [68-70]. In accord, during the resolution phase a significant negative correlation between airway wall and airway lumen eosinophils was observed [68].

\section{Mast cells}

In 1992 Juliusson and co-workers [71] made the interesting observation that the number of mast cells in allergenchallenged individuals with seasonal allergic rhinitis 
increased progressively in the nasal epithelium during ten hours following provocation. Importantly, with a delay of about two hours also the nasal airway lumen mast cells exhibited a progressive increase in numbers. As with many other aspects of nasal mucosal inflammatory responses [72] this transepithelial exit of mast cells could well reflect what would occur also in the allergic bronchi. Studies involving allergic asthmatics support this possibility. Crimi et al [73] reported a significant correlation ( $\mathrm{r}$ $=0.8$; $<0.001)$ between the number of superficial mucosal mast cells in bronchial biopsies and the severity of a resolving allergen challenge-induced late phase asthmatic reaction. Furthermore, Gauvreau et al [74] then demonstrated that mast cell numbers in the bronchial lumen correlated with the magnitude of an allergen challenge-induced late phase reaction that had occurred many hours previously. These observations in human nasal and bronchial airways suggest that epithelial transmigration of mast cells is a facet of resolution of the allergic late phase airway inflammation.

\section{Lymphocytes and dendritic cells}

In agreement with the possibility that lymphocytes are eliminated by transepithelial migration [3] Lommatzsch et al [75] have demonstrated peak numbers of lymphocytes in the airway lumen during the resolution phase several hours post allergen challenge in asthmatics. Also dendritic cells may in part be eliminated by exit into the airway lumen. When sampling inhaled allergens dendritic cells must extend processes through the epithelial tight junction barrier while maintaining the tight seal [76]. However, following allergen exposure there is also a marked increase in fully transmigrated dendritic cells in the airway lumen in animals and man [77-79]. The exit into the lumen is not immediate but is evident several hours post challenge in patients with allergic asthma [79]. It is as yet unclear what role these cells may play in the airway lumen. It has been speculated that some lumen dendritic cells may sample allergen and migrate back into the mucosa and to regional lymph nodes and that some may maintain local secondary immune responses for prolonged times after allergen exposure. Although the possibility may not have been discussed previously, even when relatively marked increases in lumen dendritic cells have occurred, it cannot be excluded that exit of mature and immature dendritic cells into the airway lumen in asthma and COPD $[79,80]$ represents a mode of elimination of these cells from the airways.

\section{Neutrophils}

Lommatzsch et al [75] have demonstrated that neutrophils exhibit peak numbers in the airway lumen during the resolution phase several hours post allergen challenge in asthmatics with mild disease. Otherwise it is severe asthma that is characterised by airway neutrophilia $[81,82]$. In a study involving patients with acute severe asthma requiring intubation, tracheal aspirates were obtained continuously until extubation [83]. "Unexpectedly", the clinical improvement in these patients was associated with a marked increase in the numbers of airway lumen neutrophils over several days until exubation. We have not found any reports that contradict this important finding. These data, obtained in resolving severe asthma, may rather be compared to the increase in airway lumen neutrophils and lymphocytes that occurs over several months in COPD along with clinical improvement after smoking cessation $[84,85]$.

Since the transepithelial passage of leukocytes has been considered a pathogenic process these observations have remained unexplained. We submit that the above clinical data on occurrence in the airway lumen of a range of immune cells in mild and severe asthma and in COPD reflect the role of transepithelial exit as a mode of ridding diseased bronchial tissues of inflammatory cells.

\section{Altered transepithelial migration in chronic airways disease} An increased airway wall chemo-attraction would recruit granulocytes from the microcirculation but also retain these cells in the wall. In severe exacerbations of COPD up to a 100-fold upregulation of neutrophil chemoattractants in bronchial mucosal tissues may thus explain the airway wall neutrophilia in these patients [86]. It further appears that neutrophil chemo-attraction in the airway lumen in COPD is abnormally low [87] and that neutrophils in severe COPD exhibit reduced chemotaxis compared to neutrophils in mild COPD [87]. Thus, increased attraction and retention of neutrophils in the airway wall, together with reduced neutrophil migration ability, could act in concert to modulate trans-epithelial egression of these cells in severe COPD. At exacerbations of COPD, a patchy occurrence of infected or injured bronchial epithelial cells $[67,88]$ could bring large numbers of neutrophils to the airway lumen. This is an important innate immunity response. Patients with COPD, who presented with exacerbations due to either bacterial or viral infection, also exhibited airway lumen neutrophilia [89].

In stable COPD it has been noted that neutrophilia in the airway lumen can be associated with lack of neutrophilia in the airway wall [82]. Similarly, a particular subgroup of COPD patients, who have bronchitic symptoms of chronic cough and expectoration, exhibited lower airway wall eosinophil counts and higher airway lumen eosinophils than subjects with COPD without chronic bronchitis [90]. Hence, chronic conditions with decreased leukocytes in the wall and increased leukocytes in the airway lumen may be characterised by a degree of accelerated transepithelial migration. It is possible that such patients will respond particularly well on treatments that stop recruitment of circulating inflammatory cells to the airway wall. Andersson et al [91] 
recently made the observation that the most severe stage of COPD was associated with reduced numbers of mast cells in the airway wall compared to less severe COPD. This difference could not be explained by increased apoptosis of airway wall mast cells but was associated with increased numbers of mast cells in the airway lumen [91]. Hence, similar to the resolution phase after allergen challenge in rhinitis [71] and asthma [73,74] airway wall mast cells seem to be eliminated by transmigration into the airway lumen in severe COPD.

\section{Preventing transepithelial migration of leukocytes aggravates inflammation}

An acknowledged research paradigm advises that inducement of eosinophil apoptosis will be of benefit in allergic airway diseases. A seminal supporting study demonstrated FAS ligand-induced eosinophil apoptosis and reduced airway lumen eosinophilia in mice with allergic inflammation [92]. We asked whether these effects in the airway lumen also involved anti-inflammatory actions in the airway wall? They did not. Although FAS treatment did produce apoptotic eosinophils also in the airway wall, this effect was associated with much increased cellular inflammation in this important location [93]. Phagocytosis of the apoptotic cells was clearly insufficient. Hence, many granulocytes underwent necrosis in the airway wall [93]. This contributed to the aggravated inflammation. In addition, reduced trans-epithelial egression of granulocytes contributed to the increased airway wall inflammation. Reduced transmigration could also explain the reduced airway lumen eosinophilia that had been repeatedly demonstrated in such FAS-treated animals. Strengthening the resolving role of transepithelial cell migration more studies have demonstrated that inhibition of transepithelial migration of granulocytes causes severe airway symptoms in allergic mice. This effect has been seen by inhibition of ICAM-2 [94] and by knock-out of matrix metalloproteinases (MMP) 2 and 9 [95,96]. In rats with virus-induced inflammation, repeated low level allergen challenges produced persistent eosinophilia in the airway wall but not in the airway lumen. The exclusive airway wall eosinophilia was associated with loss of lung elastic recoil [97]. In contrast, the allergen-exposed control rats had fewer eosinophils in the airway wall but more eosinophils in the airway lumen. They also had no loss of elastic recoil [97]. Hence, viral infections may have impeded the transepithelial exit of inflammatory cells and thus increased the effects of allergen exposure on lung mechanics. This possibility is of interest in view of the role of viral infection in exacerbations of asthma and COPD [98-100]. Human studies are warranted to explore the role of impeded transepithelial egression of leukocytes in viral induced aggravation of inflammatory airways diseases. Inhibition of transmigration should also receive attention as a mechanism and strategy by which viruses can escape host immune surveillance and defence.

Recent attempts to produce beneficial effects in COPD and asthma by reducing the traffic of granulocytes include the use of CCR inhibitors [101]. However, the possibility that such drugs may reduce egression from the diseased airway wall needs to be considered. Giving an antibody to block interleukin-5, a regulator of eosinophilopoiesis, eosinophil migration, and eosinophil survival, eliminated both blood and airway lumen eosinophilia [102] but had little effect on airway wall eosinophils [103], and no pro-apoptotic effect has been demonstrated. It is possible that the persistent airway wall eosinophilia in this situation reflected an inhibitory effect on trans-epithelial cell migration by the antibody blocking interleukin-5. Stopping both recruitment and trans-epithelial exit will result in elimination of tissue eosinophils only after a considerable delay. The extent of the delay depends on the (little known) half-life of the leukocyte in airway tissues. Observations in bronchial biopsies obtained from anti-IL-5 treated patients [103] suggest a long half-life of the airway tissue dwelling eosinophils. This inference would agree with the recent finding that clinical efficacy of anti-IL-5 treatment can be obtained in severe asthma after treatment over relatively long periods of time $[104,105]$.

\section{Pathways involved in transepithelial egression}

The human airway mucosa harbours a profuse microvascular network of capillaries and venules that receive systemic blood. Characterising the nasal mucosa and stretching all the way from the trachea to the smallest bronchioli this microcirculation occupies the area just beneath the epithelial lining. Through transendothelial migration in post-capillary venules leukocytes can thus be effectively delivered to the human airway mucosa anywhere along the nasal passages and the tracheobronchial tree. Reviews in the field of leukocyte trafficking in alveoli and airway passages in man and mice [106] often stress the fact that the low pressure pulmonary circulation differs from systemic microvascular beds by a specific sequestering of leukocytes notably the neutrophil. Location (capillary vs venular) and mechanisms (integrin independent vs dependent) involved in the extravasation of leukocytes also differ [106]. However, it seems less appreciated that the intrapulmonary airways in mice actually lack a systemic bronchial circulation [107]. Instead, these murine bronchi are fed by the pulmonary circulation. This adds to the shortcomings of the mouse models in their endeavour to mimic human asthma and COPD [108]. We have included mouse in vivo data in this review because here the focus is on the fate of the leukocytes after they have left the blood stream. Future experi- 
ments are warranted to provide data on the origin of the airway lumen leukocytes. Which vascular system has delivered them and from which part of the tracheo-bronchial-alveolar tree have they migrated?

After extravasation, leukocytes move through interstitial tissue components [109] and through the epithelial basement membrane [110]. They attach to the basal epithelium and move through relatively long stretches of epithelial cell junction complexes. Recent reviews provide updates on mechanisms and potential pathogenic roles of transepithelial migration of neutrophils [15,61,111-113]. The focus is generally on in vitro observations and the data have not been generated to shed light on elimination of airway tissue leukocytes at resolving inflammation. There is information on in vivo alveolar epithelial passage of neutrophils in the excellent review by Burns et al [111] but little is known about corresponding bronchial epithelial mechanisms. Analogous to trans-endothelial migration of leukocytes the trans-epithelial migration can be grossly viewed as a three-step event: adhesion to the barrier cells, paracellular passage, and postmigration fate [114]. In many details, however, mechanisms concerning the passage of leukocytes across the venular endothelial lining may not be similar to mechanisms regulating the transepithelial egression of leukocytes. A major difference is that the two crossings are in opposite directions: the venular para-endothelial exit is apical to basal and the epithelial passage is basal to apical. Although little is known in detail about airway epithelial transmigration of leukocytes at resolution of inflammation, some general aspects may be illustrated (Figure 1).

\section{Neutrophils}

With intestinal epithelial cells in vitro as a model, Parkos and colleagues [61,114] have described several molecular interactions between neutrophils and epithelial cells during egression from the epithelial base to the lumen surface of the epithelium. These authors also focused on pathogenic effects of the transmigration. Through CD11b/CD18 interactions with epithelial counter-receptors neutrophils adhere to the basolateral aspect of epithelial cells. The further para-epithelial passage is facilitated by a series of events opening and closing the apical junction complex. A number of adhesive interactions of neutrophils with epithelial intercellular junction proteins occur during the paracellular migration. Then ICAM-1 expressed by the apical epithelial membrane may serve as a ligand for $\mathrm{CD} 11 \mathrm{~b} / \mathrm{CD} 18$ to keep the transmigrated neutrophil attached to the luminal surface of the epithelial lining. This tethering action could be desirable in mucosal defence but is probably not suited for the clearance of cells away from inflamed airway tissues. Importantly, intestinal epithelial cells seem to differ from airway epithelium by exhibiting barrier damage in association with neutrophil transmigration [112].

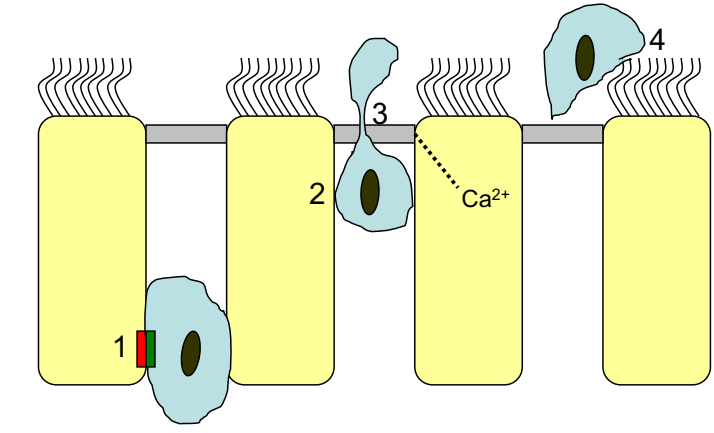

Figure 1 "Schematic representation of trans-epithelial loss of leukocytes into airway lumen". Modified from references $[61,16,112]$.

This scheme identifies some of the steps where future research is warranted to delineate mechanisms involved in the trans-epithelial elimination of inflammatory cells from the airway wall. 1 After cell-to-cell contact at the epithelial base paraepithelial crawling of the leukocyte may begin by integrin binding to desmosomal junction adhesion molecules. 2 Several binding interactions and cellular signalling events including cytosolic $\mathrm{Ca}++$ fluxes may be involved as the leukocyte continues to migrate between juxtapositioned epithelial cells. 3 Binding interactions involving junction adhesion-like proteins and receptors such as the coxsackie and adenovirus receptor may be involved in protein-tight passage of the leukocyte through the tight apical junction complex. 4 After its elimination from the airway wall the leukocyte mixes with epithelial lining fluids and is finally eliminated by mucociliary clearance.

\section{Eosinophils}

By creating transepithelial chemokine gradients, MMP 2 and 9 may produce transepithelial loss of lung parenchymal eosinophils and other leukocytes in allergic mice $[95,96]$. Increased lumen levels of CCL11 have been associated with acute loss of mucosal eosinophils into the tracheal lumen in allergen-challenged guinea-pigs [115]. In vitro observations further suggest that eotaxin-3, produced by IL-4 stimulated airway epithelial cells, and eosinophil expression of CCR3 mediate transepithelial migration [19]. CCL5 may also contribute. TNF-alpha may promote transepithelial migration in vitro of both eosinophils and neutrophils whereas IL-4 increased eosinophil but reduced neutrophil transepithelial migration [19].

\section{Lymphocytes}

Porter and colleagues [3,17] demonstrated non-injurious migration of lymphocytes across human cultured bronchial epithelium. They suggested that polarized epithelial localisation of chemokine ligands, including CCXCL10 [116] and CXCL11, to the epithelial apex determined elimination of CCR7+ T-lymphocytes from the airway wall [17]. Whereas these ligands may operate in COPD $[17,116]$, previous workers have suggested that polarized epithelial localisation of CCL5 may regulate transepithelial migration of lymphocytes in asthmatic bronchi [117]. "Chemorepellents" [118,119] might aid the trans-epithe- 
lial exit of lymphocytes and other leukocytes. In accord with this possibility, Caulfield et al [120] have suggested that steroid-induced up-regulation of CXCR4 receptors may move leukocytes away from inflamed airways in asthma.

\section{Clearance of cells from the airway lumen is essential}

The potential role of trans-epithelial egression in resolution of inflammation underlines the importance of cell clearance from the airway lumen. Clearing airway wall leukocytes across the nasal [72] and bronchial epithelium may be followed by swift and uneventful final elimination from the lumen. Due to the lack of a mucociliary escalator and lack of effect of coughing, clearance of leukocytes across the alveolar epithelium may be more problematic. Yet, in studies of lung inflammation in mice it appears that egression of parenchymal leukocytes into the alveolar air space is significantly beneficial; when this transepithelial egression was prevented severe asphyxia resulted $[95,96]$. We need to know to what extent apoptosis-related mechanisms can effect clearance of cellular exudates from the bronchial as well as the alveolar lumen. Interventions that can improve mucociliary clearance [121-125] need increased attention. It is particularly important that human peripheral airways can be freed from leukocyte- and plasma protein-rich exudates that otherwise will contribute to small airway closure $[14,126,127]$.

\section{Use of sputum cell counts to adjust treatment}

Analysis of induced sputum has advantages over determination of exhaled NO that recently was deemed to be of little value as a guide to treatment interventions in asthma [128]. Studies involving sequential sampling of sputum in stable disease suggest that leukocyte counts in induced sputum samples may exhibit acceptable repeatability $[129,130]$. These data support the use of induced sputum in monitoring disease severity and evaluating anti-inflammatory treatments in stable asthma and COPD. Of significant interest is the possibility that sputum indices can predict disease exacerbations. This is an area where sputum analysis has fared better than a clinical strategy involving symptoms and spirometry [131135]. Since the first successful study of inhaled steroids half a century ago sputum eosinophilia has shown its value in predicting which patients will benefit from treatment with these drugs. In a matter of days to weeks after instituting steroid treatment both airway wall and lumen eosinophils will be much reduced. Adjusting the steroid dose to keep sputum eosinophil counts low successfully reduces the exacerbation rate in asthma [131-133]. However, as stated by Jayaram et al [133] "the observation that treatment to control sputum eosinophilia reduced eosinophilic exacerbations may not be a surprise, since treatment was designed to prevent these" (in this case by keeping sputum eosinophils $<2 \%$ ). It might also be expected that the exacerbations that follow from tapering steroid doses can be predicted by sputum eosinophils[134,135]. Interestingly, loss of control of asthma following rapid withdrawal of steroids was associated with increased sputum neutrophils [136]. Reduced sputum neutrophilia was also helpful as an index of therapeutic effects of clarithromycin in refractory asthma [137]. It is of note that sputum data, even better than bronchial biopsy data, have identified individuals with regard to risks for exacerbation [138]. This observation may reflect the fact that sputum samples represent cumulative events over a large surface area involving also more peripheral airways than those available to biopsies. At growing inflammation, the airway wall is increasingly infiltrated with cells. A portion of these cells will migrate into the lumen. In this situation the epithelial transmigration does not reflect a resolving airway inflammation. However, a 'spill-over' of cells would be recorded in sputum samples as a sign of an arriving exacerbation. Future studies specifically addressing the relationship between airway lumen and airway wall eosinophils in developing exacerbations are warranted to further elucidate this possibility.

Leukocytes in the bronchial lumen in asthma and COPD may differ between large and small bronchiolaralveolar airways. In accord there are differences as regards the relative proportions of different leukocytes occurring in sputum specimens and broncho-alveolar lavage (BAL) fluids, respectively $[139,140]$. This is a concern since much of the pathology of asthma and COPD resides in the small airways. Tillie-Leblond and colleagues [141] further noted that only half of ten studies on the subject could demonstrate a relationship between eosinophils in induced sputum samples and symptoms of asthma. Caution is also advised in interpretation of sputum data since airway tissue and lumen may differ as to which granulocyte, eosinophil or neutrophil $[81,82]$, and which T lymphocyte, especially Tc1 or Tc2 [116,142-144], is predominant. Irrespective of such differences, it is commonly assumed that numbers of leukocytes in sputum samples reflect intensity of cell-mediated inflammatory processes in diseased bronchial tissues. The present hypothesis infers that the timing of obtaining samples in relation to developing and resolving disease conditions is crucial. Thus, during development of inflammation the cell content of sputum samples may underestimate bronchial tissue cellularity. Reversely, during an active resolution phase when cells are being eliminated from the airway wall the sputum samples could grossly overstate the numbers of airway wall cells. Awareness of this confounding possibility may improve interpretation of sputum data. 
We have introduced a dual induction method [66] whereby inhalation of histamine first induces a prompt bronchial plasma exudation response. About an hour later a second induction, this time of sputum, is employed. The induced sputum then retrieves the exuded plasma together with other mucosal interstitial proteins that the travelling plasma may have picked up. This technique can improve the protein yield of induced sputum and be employed to examine the pharmacology of plasma exudation and the occurrence of exudative hyperresponsiveness. Although the laying down of exuded plasma proteins (including fibronectin and fibrin) may pave the way for cell traffic cells cannot be expected to migrate into the airway lumen along with the bulk plasma. Perhaps other inhalational challenges than histamine can be developed that safely will bring cells into the airway lumen to improve the cellular yield of a subsequent sputum induction. As a bonus this work could lead to discovery of interventions that will speed up resolution of airway wall inflammation.

\section{Conclusion}

We have argued here that the occurrence of eosinophils, neutrophils, lymphocytes, and mast cells in the bronchial lumen can reflect their successful and non-injurious elimination away from cell-mediated disease areas in the airway wall. Evidence obtained in animal models together with a large variety of clinical observations, previously considered unexpected, support the importance of egression as a mode of eliminating pro-inflammatory leukocytes from diseased airway tissues. These clinical reports have been publicised during the last two decades. Simultaneously, the central role of leukocyte apoptosis in resolution of airway diseases that we and others have been seeking has not been confirmed. The possibility of resolution through transepithelial exit of cells needs consideration in studies of airway diseases and when assessing the effects of drug interventions. Otherwise, data on airway lumen leukocytes alone can lead to paradoxical conclusions. Inhibiting pro-inflammatory, inciting processes in the airways is important and so is rapid and complete healing of epithelial injury [67]. However, it may not suffice to reduce recruitment of inflammatory leukocytes to the airway wall. We suggest that additional effects of promoting transepithelial migration, together with a secured clearance of cells from the airway lumen, are important for accomplishing resolution of cell-mediated airways diseases.

\section{Authors' contributions}

CP prepared the first draft. LU contributed several versions, made the figure, and both approved the final manuscript.

\section{Competing interests}

The authors declare that they have no competing interests.

\section{Acknowledgements}

Our work on the present hypothesis is supported by the Swedish Medical Research Council, the Swedish Lung and Heart Foundation, and Vinnova.

\section{Author Details}

1 Department of Clinical Pharmacology, Lund University Hospital, S-22185 Lund, Sweden and 2Department of Experimental Medical Science BMC D12, Lund University, Lund, S-22184 Sweden

Received: 14 February 2010 Accepted: 11 June 2010

Published: 11 June 2010

\section{References}

1. Serhan CN, Brain SD, Buckley CD, Gilroy DW, Haslett C, O'Neill LA, Perrett $M$, Rossi AG, Wallace JL: Resolution of inflammation: state of the art, definitions and terms. FASEB J 2007, 21(2):325-332

2. Downey DG, Bell SC, Elborn JS: Neutrophils in cystic fibrosis. Thorax 2009, 64(1):81-88

3. Porter JC: Epithelial Rho GTPases and the transepithelial migration of lymphocytes. Methods Enzymol 2008, 439:205-217.

4. Persson CG: In vivo veritas: the continuing importance of discoveries in complex biosystems. Thorax 1996, 51(4):441-443.

5. Persson C: Discoveries in complex biosystems. Nat Biotechnol 1997, 15(10):927.

6. Persson CG, Erjefalt JS, Uller L, Andersson M, Greiff L: Unbalanced research. Trends Pharmaco/Sci 2001, 22(10):538-541.

7. Persson CG, Erjefalt JS: Eosinophil lysis and free granules: an in vivo paradigm for cell activation and drug development. Trends Pharmacol Sci 1997, 18(4):117-123.

8. Uller L, Andersson M, Greiff L, Persson CG, Erjefalt JS: Occurrence of apoptosis, secondary necrosis, and cytolysis in eosinophilic nasal polyps. Am J Respir Crit Care Med 2004, 170(7):742-747.

9. Persson CG: Centennial notions of asthma as an eosinophilic, desquamative, exudative, and steroid-sensitive disease. Lancet 1997, 350(9083):1021-1024

10. Erjefalt JS, Persson CG: New aspects of degranulation and fates of airway mucosal eosinophils. Am J Respir Crit Care Med 2000, 161(6):2074-2085.

11. Uller L, Persson CG, Kallstrom L, Erjefalt JS: Lung tissue eosinophils may be cleared through luminal entry rather than apoptosis: effects of steroid treatment. Am J Respir Crit Care Med 2001, 164(10 Pt 1):1948-1956

12. Greiff L, Erjefalt JS, Andersson M, Svensson C, Persson CG: Generation of clusters of free eosinophil granules (Cfegs) in seasonal allergic rhinitis. Allergy 1998, 53(2):200-203.

13. Uller $L$, Persson CG, Erjefalt JS: Resolution of airway disease: removal of inflammatory cells through apoptosis, egression or both? Trends Pharmacol Sci 2006, 27(9):461-466

14. Persson C, Uller L: Roles of plasma exudation in asthma and COPD. Clin Exp Allergy 2009, 39(11):1626-1629.

15. Zemans RL, Colgan SP, Downey GP: Transepithelial migration of neutrophils: mechanisms and implications for acute lung injury. Am J Respir Cell Mol Biol 2009, 40(5):519-535.

16. Erjefalt JS, Uller L, Malm-Erjefalt M, Persson CG: Rapid and efficient clearance of airway tissue granulocytes through transepithelial migration. Thorax 2004, 59(2):136-143.

17. Porter JC, Falzon M, Hall A: Polarized localization of epithelial CXCL11 in chronic obstructive pulmonary disease and mechanisms of T cell egression. J Immunol 2008, 180(3):1866-1877.

18. Liu L, Mul FP, Lutter R, Roos D, Knol EF: Transmigration of human neutrophils across airway epithelial cell monolayers is preferentially in the physiologic basolateral-to-apical direction. Am J Respir Cell Mol Biol 1996, 15(6):771-780

19. Kato Y, Fujisawa T, Shibano M, Saito T, Gatto W, Kamiya H, Hirai K, Sumida $\mathrm{M}$, Yoshie O: Airway epithelial cells promote transmigration of eosinophils in a new three-dimensional chemotaxis model. Clin Exp Allergy 2002, 32(6):889-897.

20. Lehmann C, Wilkening A, Leiber D, Markus A, Krug N, Pabst R, Tschernig T: Lymphocytes in the bronchoalveolar space reenter the lung tissue by means of the alveolar epithelium, migrate to regional lymph nodes, and subsequently rejoin the systemic immune system. Anat Rec 2001 264(3):229-236 
21. Erjefalt I, Luts A, Persson CG: Appearance of airway absorption and exudation tracers in guinea pig tracheobronchial lymph nodes. J App/ Physiol 1993, 74(2):817-824.

22. Korsgren M, Erjefalt JS, Korsgren O, Sundler F, Persson CG: Allergic eosinophil-rich inflammation develops in lungs and airways of B celldeficient mice. J Exp Med 1997, 185(5):885-892.

23. Buckley CD, Ross EA, McGettrick HM, Osborne CE, Haworth O, Schmutz C, Stone PC, Salmon M, Matharu NM, Vohra RK, Nash GB, Rainger GE: Identification of a phenotypically and functionally distinct population of long-lived neutrophils in a model of reverse endothelial migration. J Leukoc Biol 2006, 79(2):303-311.

24. McGettrick HM, Hunter K, Moss PA, Buckley CD, Rainger GE, Nash GB: Direct observations of the kinetics of migrating $T$ cells suggest active retention by endothelial cells with continual bidirectional migration. $J$ Leukoc Biol 2009, 85(1):98-107.

25. Haworth O, Buckley CD: Resolving the problem of persistence in the switch from acute to chronic inflammation. Proc Natl Acad Sci USA 2007, 104(52):20647-20648.

26. Uller L, Lloyd CM, Rydell-Tormanen K, Persson CG, Erjefalt JS: Effects of steroid treatment on lung CC chemokines, apoptosis and transepithelial cell clearance during development and resolution of allergic airway inflammation. Clin Exp Allergy 2006, 36(1):111-121.

27. Uller L, Ahlstrom Emanuelsson C, Andersson M, Erjefalt JS, Greiff L, Persson CG: Early phase resolution of mucosal eosinophilic inflammation in allergic rhinitis. Respir Res 2010, 11(1):54.

28. Spinozzi F, de Benedictis D, de Benedictis FM: Apoptosis, airway inflammation and anti-asthma therapy: from immunobiology to clinical application. Pediatr Allergy Immunol 2008, 19(4):287-295.

29. Wallen N, Kita H, Weiler D, Gleich GJ: Glucocorticoids inhibit cytokinemediated eosinophil survival. J Immunol 1991, 147(10):3490-3495.

30. Brunetti M, Martelli N, Colasante A, Piantelli M, Musiani P, Aiello FB: Spontaneous and glucocorticoid-induced apoptosis in human mature T lymphocytes. Blood 1995, 86(11):4199-4205.

31. Wissinger $E$, Goulding J, Hussell T: Immune homeostasis in the respiratory tract and its impact on heterologous infection. Semin Immunol 2009, 21(3):147-155.

32. Uller L, Bedke N, Sammut D, Green B, Howarth P, Holgate S, Davies D: Double-stranded RNA induces disproportionate expression of thymic stromal lymphopoietin versus interferon-beta in bronchial epithelial cells from asthmatic donors. Thorax 2010.

33. Larche M: Regulatory T cells in allergy and asthma. Chest 2007, 132(3):1007-1014

34. Murdoch JR, Lloyd CM: Chronic inflammation and asthma. Mutat Res 2009

35. Dumas A, Pouliot M: [Neutrophil: foe or friend?]. Med Sci (Paris) 2009 25(8-9):699-704.

36. Lawrence $T$, Fong $C$ : The resolution of inflammation: Anti-inflammatory roles for NF-kappaB. Int J Biochem Cell Bio/ 2009, 42(4):519-23.

37. Anderson P: Post-transcriptional regulons coordinate the initiation and resolution of inflammation. Nat Rev Immuno/ 10(1):24-35.

38. Van Hove CL, Maes T, Joos GF, Tournoy KG: Chronic inflammation in asthma: a contest of persistence vs resolution. Allergy 2008, 63(9):1095-1109.

39. Woolley KL, Gibson PG, Carty K, Wilson AJ, Twaddell SH, Woolley MJ: Eosinophil apoptosis and the resolution of airway inflammation in asthma. Am J Respir Crit Care Med 1996, 154(1):237-243.

40. Gibson PG, Saltos N, Fakes K: Acute anti-inflammatory effects of inhaled budesonide in asthma: a randomized controlled trial. Am J Respir Crit Care Med 2001, 163(1):32-36.

41. Walsh GM: Defective apoptotic cell clearance in asthma and COPD--a new drug target for statins? Trends Pharmacol Sci 2008, 29(1):6-11.

42. Rytila P, Plataki M, Bucchieri F, Uddin M, Nong G, Kinnula VL, Djukanovic R: Airway neutrophilia in COPD is not associated with increased neutrophil survival. Eur Respir J 2006, 28(6):1163-1169.

43. Watt AP, Courtney J, Moore J, Ennis M, Elborn JS: Neutrophil cell death, activation and bacterial infection in cystic fibrosis. Thorax 2005 60(8):659-664.

44. Watt AP, Brown V, Courtney J, Kelly M, Garske L, Elborn JS, Ennis M Neutrophil apoptosis, proinflammatory mediators and cell counts in bronchiectasis. Thorax 2004, 59(3):231-236.

45. Matute-Bello G, Martin TR: Science review: apoptosis in acute lung injury. Crit Care 2003, 7(5):355-358.
46. Kotecha S, Mildner RJ, Prince LR, Vyas JR, Currie AE, Lawson RA, Whyte MK: The role of neutrophil apoptosis in the resolution of acute lung injury in newborn infants. Thorax 2003, 58(11):961-967.

47. Druilhe A, Wallaert B, Tsicopoulos A, Lapa e Silva JR, Tillie-Leblond I, Tonnel $A B$, Pretolani $M$ : Apoptosis, proliferation, and expression of $\mathrm{BCl}-2$, Fas, and Fas ligand in bronchial biopsies from asthmatics. Am J Respir Cell Mol Biol 1998, 19(5):747-757.

48. O'Sullivan S, Cormican L, Burke CM, Poulter LW: Fluticasone induces T cell apoptosis in the bronchial wall of mild to moderate asthmatics. Thorax 2004, 59(8):657-661

49. Hodge S, Hodge G, Holmes M, Reynolds PN: Increased airway epithelial and T-cell apoptosis in COPD remains despite smoking cessation. Eur Respir J 2005, 25(3):447-454.

50. Cox G: Glucocorticoid treatment inhibits apoptosis in human neutrophils. Separation of survival and activation outcomes. $J$ Immunol 1995, 154(9):4719-4725.

51. Gizycki MJ, Hattotuwa KL, Barnes N, Jeffery PK: Effects of fluticasone propionate on inflammatory cells in COPD: an ultrastructural examination of endobronchial biopsy tissue. Thorax 2002, 57(9):799-803.

52. Bourbeau J, Christodoulopoulos P, Maltais F, Yamauchi Y, Olivenstein R, Hamid Q: Effect of salmeterol/fluticasone propionate on airway inflammation in COPD: a randomised controlled trial. Thorax 2007, 62(11):938-943.

53. Reid DW, Wen Y, Johns DP, Williams TJ, Ward C, Walters EH: Bronchodilator reversibility, airway eosinophilia and anti-inflammatory effects of inhaled fluticasone in COPD are not related. Respirology 2008, 13(6):799-809.

54. Fukakusa M, Bergeron $C$, Tulic MK, Fiset PO, Al Dewachi O, Laviolette $M$ Hamid Q, Chakir J: Oral corticosteroids decrease eosinophil and CC chemokine expression but increase neutrophil, IL-8, and IFN-gammainducible protein 10 expression in asthmatic airway mucosa. J Allergy Clin Immunol 2005, 115(2):280-286.

55. Nguyen LT, Lim S, Oates T, Chung KF: Increase in airway neutrophils after oral but not inhaled corticosteroid therapy in mild asthma. Respir Med 2005, 99(2):200-207.

56. Qiu Y, Zhu J, Bandi V, Guntupalli KK, Jeffery PK: Bronchial mucosal inflammation and upregulation of CXC chemoattractants and receptors in severe exacerbations of asthma. Thorax 2007, 62(6):475-482.

57. Ozol D, Aysan T, Solak ZA, Mogulkoc N, Veral A, Sebik F: The effect of inhaled corticosteroids on bronchoalveolar lavage cells and IL-8 levels in stable COPD patients. Respir Med 2005, 99(12):1494-1500.

58. Barnes NC, Qiu YS, Pavord ID, Parker D, Davis PA, Zhu J, Johnson M, Thomson NC, Jeffery PK: Antiinflammatory effects of salmeterol/ fluticasone propionate in chronic obstructive lung disease. Am J Respir Crit Care Med 2006, 173(7):736-743.

59. Vagaggini B, Cianchetti S, Bartoli M, Ricci M, Bacci E, Dente FL, Di Franco A, Paggiaro P: Prednisone blunts airway neutrophilic inflammatory response due to ozone exposure in asthmatic subjects. Respiration 2007, 74(1):61-68

60. Alexis NE, Lay JC, Haczku A, Gong H, Linn W, Hazucha MJ, Harris B, TalSinger R, Peden DB: Fluticasone propionate protects against ozoneinduced airway inflammation and modified immune cell activation markers in healthy volunteers. Environ Health Perspect 2008, 116(6):799-805.

61. Chin AC, Parkos CA: Pathobiology of neutrophil transepithelial migration: implications in mediating epithelial injury. Annu Rev Pathol 2007, 2:111-143.

62. Lukacs NW: Role of chemokines in the pathogenesis of asthma. Nat Rev Immunol 2001, 1(2):108-116.

63. Teran LM: CCL chemokines and asthma. Immunol Today 2000 21(5):235-242

64. Moraes TJ, Rafii B, Niessen F, Suzuki T, Martin R, Vachon E, Vogel W, Ruf W, O'Brodovich H, Downey GP: Protease-activated receptor (Par) 1 alters bioelectric properties of distal lung epithelia without compromising barrier function. Exp Lung Res 2009, 35(2):136-154.

65. Martin TR: Neutrophils and lung injury: getting it right. J Clin Invest 2002, 110(11):1603-1605.

66. Persson CG, Erjefalt JS, Greiff L, Andersson M, Erjefalt I, Godfrey RW, Korsgren $M$, Linden M, Sundler F, Svensson C: Plasma-derived proteins in 
airway defence, disease and repair of epithelial injury. Eur Respir J 1998, 11(4):958-970

67. Persson C, Andersson M, Uller L: Epithelial repair and function. In Pulmonary Epithelium Edited by: Proud D. Chicester: Wiley; 2008:75-88,

68. Aalbers R, de Monchy JG, Kauffman HF, Smith M, Hoekstra Y, Vrugt B, Timens W: Dynamics of eosinophil infiltration in the bronchial mucosa before and after the late asthmatic reaction. Eur Respir J 1993, 6(6):840-847.

69. Frew AJ, St-Pierre J, Teran LM, Trefilieff A, Madden J, Peroni D, Bodey KM, Walls AF, Howarth PH, Carroll MP, Holgate ST: Cellular and mediator responses twenty-four hours after local endobronchial allergen challenge of asthmatic airways. J Allergy Clin Immunol 1996, 98(1):133-143

70. Brown JR, Kleimberg J, Marini M, Sun G, Bellini A, Mattoli S: Kinetics of eotaxin expression and its relationship to eosinophil accumulation and activation in bronchial biopsies and bronchoalveolar lavage (BAL) of asthmatic patients after allergen inhalation. Clin Exp Immunol 1998, 114(2):137-146.

71. Juliusson S, Pipkorn U, Karlsson G, Enerback L: Mast cells and eosinophils in the allergic mucosal response to allergen challenge: changes in distribution and signs of activation in relation to symptoms. J Allergy Clin Immunol 1992, 90(6 Pt 1):898-909.

72. Persson CG, Svensson C, Greiff L, Anderson M, Wollmer P, Alkner U, Erjefalt I: The use of the nose to study the inflammatory response of the respiratory tract. Thorax 1992, 47(12):993-1000.

73. Crimi E, Chiaramondia M, Milanese M, Rossi GA, Brusasco V: Increased numbers of mast cells in bronchial mucosa after the late-phase asthmatic response to allergen. Am Rev Respir Dis 1991, 144(6):1282-1286

74. Gauvreau GM, Lee JM, Watson RM, Irani AM, Schwartz LB, O'Byrne PM: Increased numbers of both airway basophils and mast cells in sputum after allergen inhalation challenge of atopic asthmatics. Am J Respir Crit Care Med 2000, 161(5):1473-1478.

75. Lommatzsch M, Julius P, Kuepper M, Garn H, Bratke K, Irmscher S, Luttmann W, Renz H, Braun A, Virchow JC: The course of allergeninduced leukocyte infiltration in human and experimental asthma. $J$ Allergy Clin Immunol 2006, 118(1):91-97.

76. Ichiyasu H, McCormack JM, McCarthy KM, Dombkowski D, Preffer Fl, Schneeberger EE: Matrix metalloproteinase-9-deficient dendritic cells have impaired migration through tracheal epithelial tight junctions. Am J Respir Cell Mol Biol 2004, 30(6):761-770.

77. Lambrecht BN, Carro-Muino I, Vermaelen K, Pauwels RA: Allergeninduced changes in bone-marrow progenitor and airway dendritic cells in sensitized rats. Am J Respir Cell Mol Biol 1999, 20(6):1165-1174

78. Vermaelen K, Pauwels R: Accelerated airway dendritic cell maturation, trafficking, and elimination in a mouse model of asthma. Am J Respir Cell Mol Biol 2003, 29(3 Pt 1):405-409.

79. Bratke K, Lommatzsch M, Julius P, Kuepper M, Kleine HD, Luttmann W, Christian Virchow J: Dendritic cell subsets in human bronchoalveolar lavage fluid after segmental allergen challenge. Thorax 2007, 62(2):168-175.

80. Bratke K, Klug M, Bier A, Julius P, Kuepper M, Virchow JC, Lommatzsch M: Function-associated surface molecules on airway dendritic cells in cigarette smokers. Am J Respir Cell Mol Biol 2008, 38(6):655-660.

81. Wenzel SE: Asthma: defining of the persistent adult phenotypes. Lancet 2006, 368(9537):804-813.

82. O'Donnell R, Breen D, Wilson S, Djukanovic R: Inflammatory cells in the airways in COPD. Thorax 2006, 61(5):448-454

83. Ordonez CL, Shaughnessy TE, Matthay MA, Fahy JV: Increased neutrophil numbers and IL-8 levels in airway secretions in acute severe asthma: Clinical and biologic significance. Am J Respir Crit Care Med 2000, 161(4 Pt 1):1185-1190.

84. Louhelainen N, Rytila P, Haahtela T, Kinnula VL, Djukanovic R: Persistence of oxidant and protease burden in the airways after smoking cessation. BMC Pulm Med 2009, 9:25.

85. Willemse BW, ten Hacken NH, Rutgers B, Lesman-Leegte IG, Postma DS, Timens W: Effect of 1-year smoking cessation on airway inflammation in COPD and asymptomatic smokers. Eur Respir J 2005, 26(5):835-845.

86. Qiu Y, Zhu J, Bandi V, Atmar RL, Hattotuwa K, Guntupalli KK, Jeffery PK: Biopsy neutrophilia, neutrophil chemokine and receptor gene expression in severe exacerbations of chronic obstructive pulmonary disease. Am J Respir Crit Care Med 2003, 168(8):968-975.
87. Yoshihara S, Yamada Y, Abe T, Linden A, Arisaka O: Association of epithelial damage and signs of neutrophil mobilization in the airways during acute exacerbations of paediatric asthma. Clin Exp Immunol 2006, 144(2):212-216

88. Mosser AG, Brockman-Schneider R, Amineva S, Burchell L, Sedgwick JB, Busse WW, Gern JE: Similar frequency of rhinovirus-infectible cells in upper and lower airway epithelium. J Infect Dis 2002, 185(6):734-743.

89. Papi A, Bellettato CM, Braccioni F, Romagnoli M, Casolari P, Caramori G, Fabbri LM, Johnston SL: Infections and airway inflammation in chronic obstructive pulmonary disease severe exacerbations. Am J Respir Crit Care Med 2006, 173(10):1114-1121.

90. Snoeck-Stroband JB, Lapperre TS, Gosman MM, Boezen HM, Timens W ten Hacken NH, Sont JK, Sterk PJ, Hiemstra PS: Chronic bronchitis subphenotype within COPD: inflammation in sputum and biopsies. Eur Respir J 2008, 31(1):70-77.

91. Andersson CK, Mori M, Bjermer L, Lofdahl CG, Erjefalt JS: Alterations in lung mast cell populations in patients with chronic obstructive pulmonary disease. Am J Respir Crit Care Med 2010, 181(3):206-217.

92. Tsuyuki S, Bertrand C, Erard F, Trifilieff A, Tsuyuki J, Wesp M, Anderson GP, Coyle AJ: Activation of the Fas receptor on lung eosinophils leads to apoptosis and the resolution of eosinophilic inflammation of the airways. J Clin Invest 1995, 96(6):2924-2931.

93. Uller L, Rydell-Tormanen K, Persson CG, Erjefalt JS: Anti-Fas mAb-induced apoptosis and cytolysis of airway tissue eosinophils aggravates rather than resolves established inflammation. Respir Res 2005, 6:90.

94. Gerwin N, Gonzalo JA, Lloyd C, Coyle AJ, Reiss Y, Banu N, Wang B, Xu H, Avraham $\mathrm{H}$, Engelhardt $\mathrm{B}$, et al:: Prolonged eosinophil accumulation in allergic lung interstitium of ICAM-2 deficient mice results in extended hyperresponsiveness. Immunity 1999, 10(1):9-19.

95. Corry DB, Kiss A, Song LZ, Song L, Xu J, Lee SH, Werb Z, Kheradmand F: Overlapping and independent contributions of MMP2 and MMP9 to lung allergic inflammatory cell egression through decreased $\mathrm{CC}$ chemokines. FASEB J 2004, 18(9):995-997.

96. Corry DB, Rishi K, Kanellis J, Kiss A, Song Lz LZ, Xu J, Feng L, Werb Z, Kheradmand $F$ : Decreased allergic lung inflammatory cell egression and increased susceptibility to asphyxiation in MMP2-deficiency. Nat Immunol 2002, 3(4):347-353.

97. Sorkness RL, Herricks KM, Szakaly RJ, Lemanske RF Jr, Rosenthal LA Altered allergen-induced eosinophil trafficking and physiological dysfunction in airways with preexisting virus-induced injury. Am J Physiol Lung Cell Mol Physiol 2007, 292(1):L85-91.

98. Rohde G, Wiethege A, Borg I, Kauth M, Bauer TT, Gillissen A, Bufe A, Schultze-Werninghaus $G$ : Respiratory viruses in exacerbations of chronic obstructive pulmonary disease requiring hospitalisation: a case-control study. Thorax 2003, 58(1):37-42.

99. Johnston SL, Pattemore PK, Sanderson G, Smith S, Lampe F, Josephs L, Symington P, O'Toole S, Myint SH, Tyrrell DA, Holgate ST: Community study of role of viral infections in exacerbations of asthma in 9-11 year old children. BMJ 1995, 310(6989):1225-1229.

100. Seemungal TA, Wedzicha JA: Viral infections in obstructive airway diseases. Curr Opin Pulm Med 2003, 9(2):111-116

101. Norman P: AZD-4818, a chemokine CCR1 antagonist: WO2008103126 and WO2009011653. Expert Opin Ther Pat 2009, 19(11):1629-1633.

102. Leckie MJ, ten Brinke A, Khan J, Diamant Z, O'Connor BJ, Walls CM, Mathur AK, Cowley HC, Chung KF, Djukanovic R, Hansel TT, Holgate ST, Sterk PJ, Barnes PJ: Effects of an interleukin-5 blocking monoclonal antibody on eosinophils, airway hyper-responsiveness, and the late asthmatic response. Lancet 2000, 356(9248):2144-2148.

103. Flood-Page P, Menzies-Gow A, Phipps S, Ying S, Wangoo A, Ludwig MS, Barnes N, Robinson D, Kay AB: Anti-IL-5 treatment reduces deposition of ECM proteins in the bronchial subepithelial basement membrane of mild atopic asthmatics. J Clin Invest 2003, 112(7):1029-1036.

104. Haldar P, Brightling CE, Hargadon B, Gupta S, Monteiro W, Sousa A, Marshall RP, Bradding P, Green RH, Wardlaw AJ, Pavord ID: Mepolizumab and exacerbations of refractory eosinophilic asthma. N Engl J Med 2009, 360(10):973-984.

105. Nair P, Pizzichini MM, Kjarsgaard M, Inman MD, Efthimiadis A, Pizzichini E, Hargreave FE, O'Byrne PM: Mepolizumab for prednisone-dependent asthma with sputum eosinophilia. N Engl J Med 2009, 360(10):985-993.

106. Doerschuk CM: Leukocyte trafficking in alveoli and airway passages. Respir Res 2000, 1(3):136-140. 
107. Mitzner W, Lee W, Georgakopoulos D, Wagner E: Angiogenesis in the mouse lung. Am J Pathol 2000, 157(1):93-101.

108. Persson CG, Erjefalt JS, Korsgren M, Sundler F: The mouse trap. Trends Pharmacol Sci 1997, 18(12):465-467.

109. Muessel MJ, Scott KS, Friedl P, Bradding P, Wardlaw AJ: CCL11 and GMCSF differentially use the Rho GTPase pathway to regulate motility of human eosinophils in a three-dimensional microenvironment. J Immunol 2008, 180(12):8354-8360.

110. Rowe RG, Weiss SJ: Breaching the basement membrane: who, when and how? Trends Cell Bio/ 2008, 18(11):560-574.

111. Burns AR, Smith CW, Walker DC: Unique structural features that influence neutrophil emigration into the lung. Physiol Rev 2003, 83(2):309-336.

112. Chun J, Prince A: Ca2+ signaling in airway epithelial cells facilitates leukocyte recruitment and transepithelial migration. J Leukoc Bio/ 2009, 86(5):1135-1144.

113. Chun J, Prince A: TLR2-induced calpain cleavage of epithelial junctional proteins facilitates leukocyte transmigration. Cell Host Microbe 2009, 5(1):47-58.

114. Zen K, Parkos CA: Leukocyte-epithelial interactions. Curr Opin Cell Biol 2003, 15(5):557-564

115. Erjefalt JS, Korsgren M, Malm-Erjefalt M, Conroy DM, Williams TJ, Persson CG: Acute allergic responses induce a prompt luminal entry of airway tissue eosinophils. Am J Respir Cell Mol Biol 2003, 29(4):439-448.

116. Saetta M, Mariani M, Panina-Bordignon P, Turato G, Buonsanti C, Baraldo S, Bellettato CM, Papi A, Corbetta L, Zuin R, et al: Increased expression of the chemokine receptor $C X C R 3$ and its ligand $C X C L 10$ in peripheral airways of smokers with chronic obstructive pulmonary disease. Am J Respir Crit Care Med 2002, 165(10):1404-1409.

117. Taguchi M, Sampath D, Koga T, Castro M, Look DC, Nakajima S, Holtzman MJ: Patterns for RANTES secretion and intercellular adhesion molecule 1 expression mediate transepithelial T cell traffic based on analyses in vitro and in vivo. J Exp Med 1998, 187(12):1927-1940

118. Cyster JG: Chemorepulsion and thymocyte emigration. J Clin Invest 2002, 109(8):1011-1012

119. Vianello F, Kraft P, Mok YT, Hart WK, White N, Poznansky MC: A CXCR4dependent chemorepellent signal contributes to the emigration of mature single-positive CD4 cells from the fetal thymus. J Immunol 2005, 175(8):5115-5125

120. Caulfield J, Fernandez M, Snetkov V, Lee T, Hawrylowicz C: CXCR4 expression on monocytes is up-regulated by dexamethasone and is modulated by autologous CD3+ T cells. Immunology 2002, 105(2):155-162

121. Button B, Boucher RC: Role of mechanical stress in regulating airway surface hydration and mucus clearance rates. Respir Physiol Neurobiol 2008, 163(1-3):189-201.

122. Daviskas E, Anderson SD, Eberl S, Chan HK, Young IH: The 24-h effect of mannitol on the clearance of mucus in patients with bronchiectasis. Chest 2001, 119(2):414-421.

123. Bhowmik A, Chahal K, Austin G, Chakravorty I: Improving mucociliary clearance in chronic obstructive pulmonary disease. Respir Med 2009, 103(4):496-502.

124. Shah RV, Amin M, Sangwan S, Smaldone GC: Steroid effects on mucociliary clearance in outpatient asthma. J Aerosol Med 2006 19(2):208-220

125. Bennett WD, Almond MA, Zeman KL, Johnson JG, Donohue JF: Effect of salmeterol on mucociliary and cough clearance in chronic bronchitis. Pulm Pharmacol Ther 2006, 19(2):96-100.

126. Sturton G, Persson C, Barnes PJ: Small airways: an important but neglected target in the treatment of obstructive airway diseases. Trends Pharmacol Sci 2008, 29(7):340-345

127. Hogg JC: Pathophysiology of airflow limitation in chronic obstructive pulmonary disease. Lancet 2004, 364(9435):709-721.

128. Szefler SJ, Mitchell H, Sorkness CA, Gergen PJ, O'Connor GT, Morgan WJ, Kattan M, Pongracic JA, Teach SJ, Bloomberg GR, Bloomberg GR, Eggleston PA, Gruchalla RS, Kercsmar CM, Liu AH, Wildfire JJ, Curry MD, Busse WW: Management of asthma based on exhaled nitric oxide in addition to guideline-based treatment for inner-city adolescents and young adults: a randomised controlled trial. Lancet 2008, 372(9643):1065-1072
129. Beeh KM, Beier J, Kornmann O, Mander A, Buhl R: Long-term repeatability of induced sputum cells and inflammatory markers in stable, moderately severe COPD. Chest 2003, 123(3):778-783.

130. Sapey E, Bayley D, Ahmad A, Newbold P, Snell N, Stockley RA: Interrelationships between inflammatory markers in patients with stable COPD with bronchitis: intra-patient and inter-patient variability. Thorax 2008, 63(6):493-499.

131. Green RH, Brightling CE, McKenna S, Hargadon B, Parker D, Bradding P, Wardlaw AJ, Pavord ID: Asthma exacerbations and sputum eosinophil counts: a randomised controlled trial. Lancet 2002, 360(9347):1715-1721.

132. Chlumsky J, Striz I, Terl M, Vondracek J: Strategy aimed at reduction of sputum eosinophils decreases exacerbation rate in patients with asthma. J Int Med Res 2006, 34(2):129-139.

133. Jayaram L, Pizzichini MM, Cook RJ, Boulet LP, Lemiere C, Pizzichini E, Cartier A, Hussack P, Goldsmith CH, Laviolette M, Parameswaran K, Hargreave FE: Determining asthma treatment by monitoring sputum cell counts: effect on exacerbations. Eur Respir J 2006, 27(3):483-494.

134. Jatakanon A, Lim S, Barnes PJ: Changes in sputum eosinophils predict loss of asthma control. Am J Respir Crit Care Med 2000, 161(1):64-72.

135. Leuppi JD, Salome CM, Jenkins CR, Anderson SD, Xuan W, Marks GB, Koskela H, Brannan JD, Freed R, Andersson M, Chan HK, Woolcock AJ: Predictive markers of asthma exacerbation during stepwise dose reduction of inhaled corticosteroids. Am J Respir Crit Care Med 2001, 163(2):406-412.

136. Maneechotesuwan K, Essilfie-Quaye S, Kharitonov SA, Adcock IM, Barnes PJ: Loss of control of asthma following inhaled corticosteroid withdrawal is associated with increased sputum interleukin-8 and neutrophils. Chest 2007, 132(1):98-105.

137. Simpson JL, Powell H, Boyle MJ, Scott RJ, Gibson PG: Clarithromycin targets neutrophilic airway inflammation in refractory asthma. Am J Respir Crit Care Med 2008, 177(2):148-155.

138. Lemiere C, Ernst P, Olivenstein R, Yamauchi Y, Govindaraju K, Ludwig MS, Martin JG, Hamid Q: Airway inflammation assessed by invasive and noninvasive means in severe asthma: eosinophilic and noneosinophilic phenotypes. J Allergy Clin Immunol 2006, 118(5):1033-1039.

139. Maestrelli P, Saetta M, Di Stefano A, Calcagni PG, Turato G, Ruggieri MP, Roggeri A, Mapp CE, Fabbri LM: Comparison of leukocyte counts in sputum, bronchial biopsies, and bronchoalveolar lavage. Am J Respir Crit Care Med 1995, 152(6 Pt 1):1926-1931.

140. Rutgers SR, Timens W, Kaufmann HF, van der Mark TW, Koeter GH, Postma DS: Comparison of induced sputum with bronchial wash, bronchoalveolar lavage and bronchial biopsies in COPD. Eur Respir 2000, 15(1):109-115.

141. Tillie-Leblond I, Montani D, Crestani B, de Blic J, Humbert M, Tunon-deLara M, Magnan A, Roche N, Ostinelli J, Chanez P: Relation between inflammation and symptoms in asthma. Allergy 2009, 64(3):354-367.

142. Barcelo B, Pons J, Fuster A, Sauleda J, Noguera A, Ferrer JM, Agusti AG: Intracellular cytokine profile of T lymphocytes in patients with chronic obstructive pulmonary disease. Clin Exp Immunol 2006, 145(3):474-479.

143. Barczyk A, Pierzchala W, Kon OM, Cosio B, Adcock IM, Barnes PJ: Cytokine production by bronchoalveolar lavage $\mathrm{T}$ lymphocytes in chronic obstructive pulmonary disease. J Allergy Clin Immunol 2006, 117(6):1484-1492

144. Freeman CM, Curtis JL, Chensue SW: CC chemokine receptor 5 and CXC chemokine receptor 6 expression by lung CD8+ cells correlates with chronic obstructive pulmonary disease severity. Am J Pathol 2007, 171(3):767-776

doi: $10.1186 / 1465-9921-11-75$

Cite this article as: Persson and Uller, Resolution of cell-mediated airways diseases Respiratory Research 2010, 11:75 